Prepared for the U.S. Department of Energy

under Contract DE-AC05-76RL01830

\title{
Facilities and Operations
}

\section{Blueprint for the Building Operations Control Center}

ST Belew

March 2014

Pacific Northwest

NATIONAL LABORATORY

Proudly Operated by Battelle Since 1965 


\title{
DISCLAIMER
}

This report was prepared as an account of work sponsored by an agency of the United States Government. Neither the United States Government nor any agency thereof, nor Battelle Memorial Institute, nor any of their employees, makes any warranty, express or implied, or assumes any legal liability or responsibility for the accuracy, completeness, or usefulness of any information, apparatus, product, or process disclosed, or represents that its use would not infringe privately owned rights. Reference herein to any specific commercial product, process, or service by trade name, trademark, manufacturer, or otherwise does not necessarily constitute or imply its endorsement, recommendation, or favoring by the United States Government or any agency thereof, or Battelle Memorial Institute. The views and opinions of authors expressed herein do not necessarily state or reflect those of the United States Government or any agency thereof.

\author{
PACIFIC NORTHWEST NATIONAL LABORATORY \\ operated by \\ BATTELLE \\ for the \\ UNITED STATES DEPARTMENT OF ENERGY \\ under Contract DE-AC05-76RL01830
}

Printed in the United States of America
Available to DOE and DOE contractors from the Office of Scientific and Technical Information,
P.O. Box 62, Oak Ridge, TN 37831-0062;
ph: (865) 576-8401
fax: $(865)$ 576-5728
email: reports@adonis.osti.gov

\begin{abstract}
Available to the public from the National Technical Information Service, U.S. Department of Commerce, 5285 Port Royal Rd., Springfield, VA 22161 ph: (800) 553-6847 fax: $(703) 605-6900$ email: orders@ntis.fedworld.gov online ordering: http://www.ntis.gov/ordering.htm
\end{abstract}

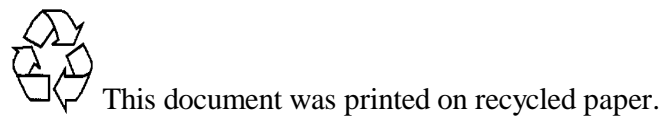




\title{
Facilities and Operations
}

\section{Blueprint for the Building Operations Control Center}

\author{
Revision \#: $\quad 0$ \\ Revision Date: $\quad$ March 2014 \\ Owner/Approval: $\quad$ M Moran \\ Author: S Belew
}

Prepared for

the U.S. Department of Energy

under Contract DE-AC05-76RL01830

Pacific Northwest National Laboratory

Richland, Washington 99352 



\section{Approvals}

\begin{tabular}{|c|c|c|}
\hline Title & Approver & Signature and Date \\
\hline $\begin{array}{l}\text { Manager: } \\
\text { Sustainability and } \\
\text { Energy Operations }\end{array}$ & Mike Moran & \\
\hline $\begin{array}{l}\text { Sustainability } \\
\text { Engineer (Author) }\end{array}$ & Shan Belew & \\
\hline
\end{tabular}

CONCURRENCE

\begin{tabular}{|l|l|l|}
\hline Title & Concurs & Signature and Date \\
\hline $\begin{array}{l}\text { Manager: Strategic } \\
\text { Project/Program }\end{array}$ & Terry Brog & \\
\hline $\begin{array}{l}\text { Chief Engineer: } \\
\text { Facility and } \\
\text { Operations }\end{array}$ & Dave Brown & \\
\hline $\begin{array}{l}\text { Manager: } \\
\text { Facility Operations } \\
\text { and Engineering } \\
\text { Division }\end{array}$ & Paul Crane & \\
\hline $\begin{array}{l}\text { Manager: } \\
\text { Plant Engineering }\end{array}$ & Tom Davis & \\
\hline $\begin{array}{l}\text { Manager: } \\
\text { Engineering }\end{array}$ & Darrell De Smet & \\
\hline $\begin{array}{l}\text { Manager: } \\
\text { Plant Operations }\end{array}$ & Reed Sharp & \\
\hline
\end{tabular}




\section{Revision History}

\begin{tabular}{|c|c|c|}
\hline Date & Rev.\# & Description \\
\hline March 2014 & 0 & Initial Release \\
\hline & & \\
\hline & & \\
\hline & & \\
\hline & & \\
\hline & & \\
\hline & & \\
\hline & & \\
\hline & & \\
\hline & & \\
\hline & & \\
\hline & & \\
\hline & & \\
\hline & & \\
\hline & & \\
\hline & & \\
\hline & & \\
\hline & & \\
\hline
\end{tabular}




\section{Executive Summary}

The Pacific Northwest National Laboratory (PNNL) Facility and Operations (F\&O) Division strives to manage performance, to assure long-term health and sustainability for the organization and our staff through innovation and learning. The $\mathrm{F} \& \mathrm{O}$ organization is committed to achieving five strategic outcomes over the next several years. The strategic outcomes are aligned with the Department of Energy (DOE) and PNNL mission and vision. One key outcome important to enabling our vision is to integrate the smartest facilities, connected to the smartest people, by the smartest systems. We call this our SMART $^{3}$ Initiative.

The F\&O SMART ${ }^{3}$ Initiative will connect human capital with intelligent systems, resulting in a bestin-class, integrated facility-operations strategy that improves productivity and optimizes operational costs. The Building Operations Control Center (BOCC) Blueprint is a key deliverable in this effort and will define near-term and long-term objectives aligned with the SMART ${ }^{3}$ Initiative. The BOCC Blueprint provides a plan to successfully position the BOCC and assure full integration into the new Systems Engineering Laboratory (SEL).

The BOCC Blueprint near-term objectives will satisfy each of the three elements of the SMART ${ }^{3}$ Initiative.

1. The facilities element will be achieved by defining the minimum set of smart sensors for deployment, establishing dashboards and metrics, and initiating a Real-Time Commissioning Program (RT-Cx).

2. The people element will be achieved as F\&O and the Energy and Environment Directorate (EED) collaborate, mentor, and cross-train within F\&O. The collaboration effort will provide proof of concept by testing, applying and sharing information on facility systems through smart grid, facility re-tuning \& audits, and DSOM fault detection and diagnostics. The mentoring and cross-training will be realized by integrating air balance operators, power operators and FMCS specialists within the BOCC.

3. The systems element will be achieved by standardizing the Facility Management Control Systems (FMCS) and Decision Support for Operations and Maintenance (DSOM) development, specifically by implementing facility dashboards and tools.

The long-term objectives are to enhance reliability, reduce cost, and demonstrate the "Living Laboratory," as defined by the way facilities are used to advance research from theoretical to practical applications through scientific collaboration among PNNL's research and development (R\&D) staff. With the BOCC Blueprint defining the objectives to meet the SMART ${ }^{3}$ Initiative, the BOCC will become a valuable PNNL core competency, and allow for additional R\&D opportunities. 



\section{Acronyms and Abbreviations}

$\begin{array}{ll}\text { BOCC } & \text { Building Operations Control Center } \\ \text { DOE } & \text { U.S. Department of Energy } \\ \text { DSOM } & \text { Decision Support for Operations \& Maintenance } \\ \text { ECM } & \text { Energy Conservation Measure } \\ \text { EED } & \text { Energy and Environment Directorate } \\ \text { EI\&B } & \text { Electricity Infrastructure and Buildings } \\ \text { EIOC } & \text { Electricity Infrastructure Operations Center } \\ \text { F\&O } & \text { Facilities and Operations } \\ \text { FMCS } & \text { Facility Management Control Systems } \\ \text { FY } & \text { fiscal year } \\ \text { HVAC } & \text { heating, ventilation, and air conditioning } \\ \text { PNNL } & \text { Pacific Northwest National Laboratory } \\ \text { R\&D } & \text { Research and Development } \\ \text { RT-Cx } & \text { Real-Time Commissioning } \\ \text { SEL } & \text { Systems Engineering Laboratory } \\ \text { TAB } & \text { testing and balancing }\end{array}$





\section{Contents}

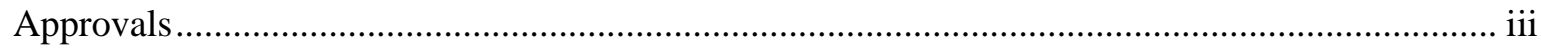

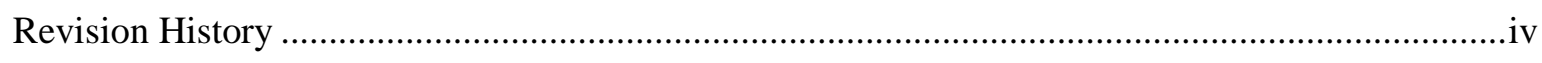

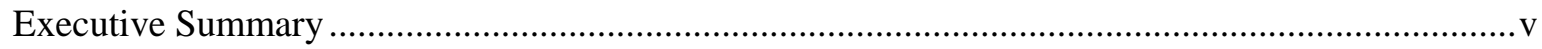

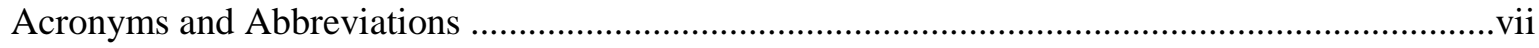

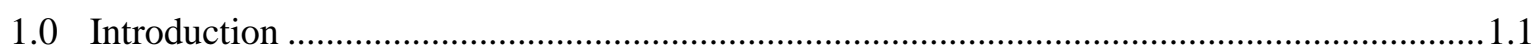

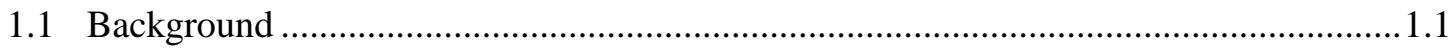

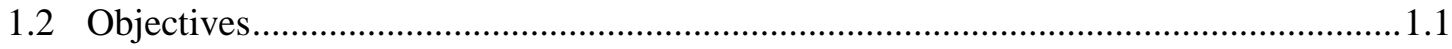

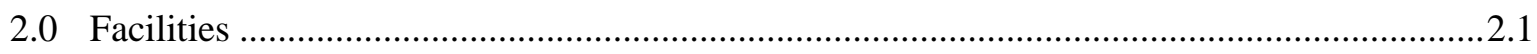

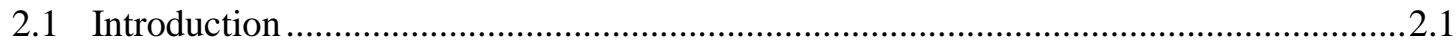

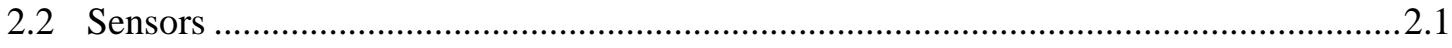

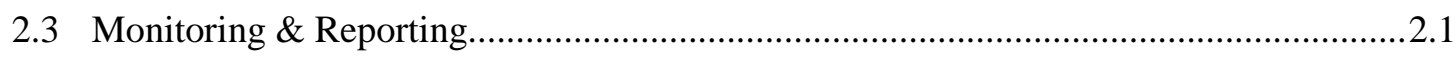

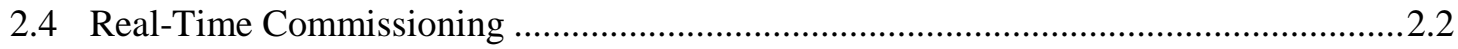

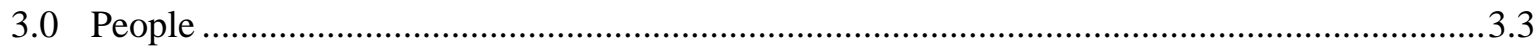

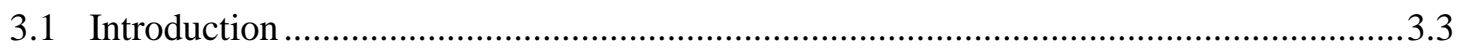

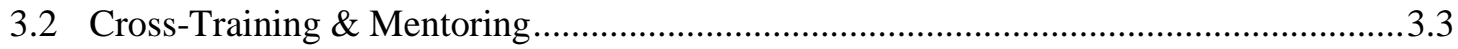

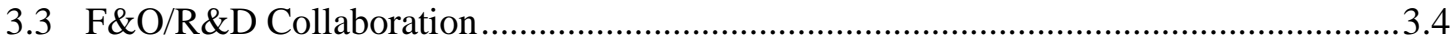

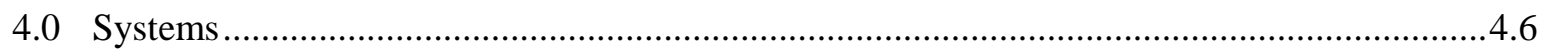

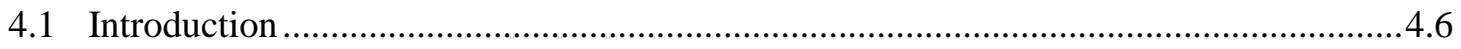

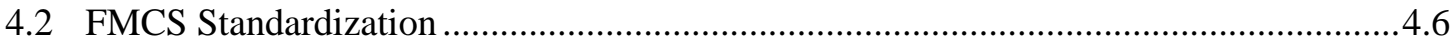

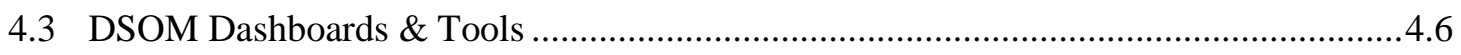

\section{Figures}

Figure 1. CBHV Tool in DSOM................................................................................. 4.7 



\subsection{Introduction}

The PNNL F\&O Division has committed to implementing what is known as the SMART ${ }^{3}$ Initiative. The goal of SMART ${ }^{3}$ Initiative is to integrate the smartest facilities, connected to the smartest people, by the smartest systems.

\section{A SMART ${ }^{3}$}

\subsection{Background}

The BOCC was established in 2011 and is located in the 350 facility. The BOCC is equipped with large screens used for displaying and monitoring data and holding meetings. The BOCC staff monitors data to optimize energy, extend asset life, and enhance the reliability and efficiency of the PNNL campus. Data is collected from the FMCS and in-house-developed R\&D software-DSOM-to perform diagnostics, trending, and analytics. These two systems are the backbone of the BOCC.

\subsection{Objectives}

The intent of the BOCC Blueprint is to provide a guide for how the BOCC can be utilized to meet the objectives to achieve the SMART ${ }^{3}$ Initiative. The BOCC Blueprint defines the near-term and long-term goals for the BOCC. The goals will be managed under the Project Management Plan (PMP) for the PNNL Sustainability Program FY2014.

The BOCC staff is an instrumental part of implementing the SMART $^{3}$ Initiative. The vision of the BOCC is to combine our human capital with our intelligent infrastructure, which will result in the BOCC becoming best-in-class and allow for PNNL to become a Living Laboratory. This will provide new R\&D opportunities and create a center for sustainable and superior operational management. The specific objects are shown below:

\section{Near-Term:}

1. Facilities:

- Defining smart sensors for deployment

- Monitoring \& reporting performance

- Developing a RT-Cx Program

2. People:

- Integrating the air balance staff with BOCC tools, data, and analytics

- BOCC staff members mentoring operators, FMCS specialists and collaborating with Engineering

- Leveraging capabilities of the PNNL R\&D 
3. Systems:

- Standardizing FMCS

- Deploying DSOM

\section{Long-Term:}

1. Enhancing configuration management

2. Moving toward condition-based maintenance

3. Fully implementing BOCC in SEL - a Living Laboratory

Conclusion: The BOCC Blueprint will enable the $\mathrm{SMART}^{3}$ Initiative by connecting facilities, systems and people. In the long-term to enhance reliability, reduce cost, and demonstrate the Living Laboratory. 


\subsection{Facilities}

\subsection{Introduction}

The goal is to create an intelligent infrastructure using real-time data to make informed decisions resulting in reduced facility operational cost. Operations costs can be reduced by using information from sensored facilities to create condition-based maintenance service requests, prevent equipment failures using real-time commissioning, and reduce energy cost by monitoring $\&$ reporting facility operations and implementing energy conservation measures.

\subsection{Sensors}

A "smart sensor" can be used in condition-based preventative maintenance applications for automated and manual diagnostics and will allow for improved operation of the facility and systems. The BOCC staff is leading the initiative to implement smart sensors by defining and deploying required sensors through a graded approach—considering value, cost effectiveness, and life cycle. The Plant Engineering Manager reviews the approach and validates the proposed sensors and plan. The BOCC staff works with Engineering to embed smart sensor requirements in design standards, for R\&D by providing access to data for research, and for Operations by providing data to aid in improving operations, helping to reduce energy usage. There are four value areas smart sensors provide:

\section{Tier I:}

Tier II

1. Improved operations (troubleshooting, trending)

2. Energy savings (monitor use, match demand)

3. Diagnostics (detects equipment fault)

4. Condition-based maintenance

Refer to the Smart Sensors plan for more information on smart sensors and how they are utilized in operations. Smart sensors are being deployed in FY14.

\subsection{Monitoring \& Reporting}

PNNL remains committed about reducing its energy use 30 percent by 2015 . To meet the 30 percent reduction goal, the BOCC staff monitors \& reports using benchmarking in energy meetings with core teams, and implementing energy conservation measures. By providing a hub for the FMCS and DSOM systems to connect with building managers, building engineers, design engineers, $R \& D$, and possibly facility occupants, the BOCC staff will be the driving force for assuring the energy goals are met through continuous monitoring and reporting.

The BOCC staff uses benchmarking to establish a baseline for energy usage in facilities, systems, and equipment. Operational costs can be reduced by comparing benchmarked data with current usage. Currently, benchmarking is performed through metered facilities with FMCS, EnergyCAP and DSOM. The data is then manually converted to Microsoft ${ }^{\circledR}$ Excel and manually analyzed. By having the ability to benchmark historical, normalized (i.e., with respect to weather, size, type) utility data, the building manager and building engineer are able to manage by exception, but also highlight the best performing 
facilities. Benchmarking is currently one of the best energy management techniques applied at PNNL. During monthly energy meetings, benchmarking is used to define the goals of each facility and also to compare facilities against one another.

To continue to reduce cost and provide additional analyzed data, it is recommended to automate exporting of the energy data. This would also allow real-time reports. This effort will require developing these features within DSOM.

To help reduce operational costs and assure that energy reduction goals are met, the BOCC staff has implemented monthly energy meetings with each core team. Major discussion points at the meetings include reviewing current energy goals and identifying operational improvements using FMCS and DSOM. The first point of discussion is to look at core team's annual energy/water consumption compared to goals and benchmark against each facility and other facilities in the core team. The second point of discussion is to use FMCS and DSOM to identify operational improvements, including no/low-cost action items and energy conservation measures. In addition, energy meetings provide a forum to share best practices across core teams.

The action items from each energy meeting are sent via email to the respective core team. The intent is for the core team to accomplish action items prior to the next energy meeting. Any action items that require additional resources, engineering, and/or installation will be added to the Master Energy Conservation Measure (ECM) List and managed accordingly.

ECMs are used to reduce facility energy consumption by identifying projects with life-cycle cost effectiveness and return on investment. ECMs can be used to substantiate upgrades on existing outdated equipment and systems to improve the overall operation of the facility. ECMs can range from no cost/low-cost sequence modifications to complete equipment replacements. The BOCC staff will collaborate with Projects and Engineering, building management and building engineers, and R\&D to identify, prioritize, and plan ECMs. The BOCC staff, through real-time commissioning and energy meetings, will provide input into the Master ECM List for each core team.

\subsection{Real-Time Commissioning}

Real-Time commissioning (RT-Cx) is a continuous, monitor-based program assuring that facility systems are functioning properly and are used to optimize operations and evaluate performance baselines. RT-Cx also allows for proactive actions to identify and correct problems before impacting occupants and research. In addition, this will reduce operating costs by reducing energy usage and the number of nuisance alarms. Deferred maintenance costs can be reduced by fixing issues as they occur, which can prevent equipment failure. RT-Cx will also allow PNNL to satisfy the contractual Energy Independence and Security Act and High Performance Sustainable Building commissioning requirements by generating final reports, capturing ongoing RT-Cx assessments for specified time periods.

The BOCC will become the center of operations for RT-Cx. The BOCC staff, along with the core team building engineers will work to document, identify, and resolve issues before affecting systems and occupants, while maintaining an ongoing record of work. The ongoing record will be critical in sharing the information with building engineers, operators, crafts and engineering for future decisions, troubleshooting, and assuring continuous commissioning. 


\subsection{People}

\subsection{Introduction}

The BOCC will be instrumental in allowing collaboration between Operations, $R \& D$, and Engineering. The BOCC will be the hub that allows collaboration to take place. The BOCC will help bring together facilities, systems and people.

\subsection{Cross-Training \& Mentoring}

To maintain a highly skilled workforce, cross-training and mentoring will occur within the BOCC. The benefit of utilizing the BOCC is access to real-time data and control on multiple large display screens. Leveraging BOCC capabilities for cross-training will allow for a higher level of training. The BOCC is the learning interface that best displays the information from the FMCS and DSOM.

In the near term, to fully utilize the BOCC, the following existing resources will either rotate or meet at a regular frequency within the BOCC. These include rotating the existing FMCS specialist through the BOCC (i.e., 1/2 day a week each month), rotating power operators on a similar frequency pairing up with the concurrent FMCS specialist. This also includes rotating the commissioning engineer into the BOCC and/or physically locating inside or adjacent to the BOCC. Also the air balance work team lead will be required to dispatch air balance operators from the BOCC to perform PMs and Testing and Balancing $(\mathrm{TAB})$.

All air balance operators will be dispatched from the BOCC by the work team lead. These positions will perform monthly PMs for the core teams and will also set testing configurations for labs (heating/cooling/occupied modes) using portable PC tablets with Metasys capability and will perform functional testing and TAB. These operators will provide verification in the field in accordance with realtime commissioning. They will also perform TAB corrective actions as needed (air/hydronic balancing and sensor calibration). Meeting with air balance operators from the BOCC will optimize the performance of PMs and TAB for all systems.

The commissioning engineer will rotate and/or function out of the BOCC. The BOCC staff will develop, implement, and document field-test procedures for lab functional testing, HVAC functional testing, and TAB Verification based on available design documentation for real-time commissioning. The commissioning engineer will be responsible for delivering final reports and implementing corrective actions and scheduling real-time commissioning activities. This is important as the long-term goal of the BOCC is to become the center of commissioning.

To enable cross-training the FMCS specialist and operator will rotate through the BOCC. During this time the FMCS specialist will complete the BOCC corrective action list from the energy meetings, make improvements and drive consistency of graphics, points and trends and identify other opportunities for improvement. The operator will integrate into real-time commissioning of systems, validate graphics, and identify opportunities for improved operations such as graphics, control points, parameters, and alarms. 


\subsection{F\&O/R\&D Collaboration}

The BOCC will be located within SEL and used as a collaboration center for F\&O and EED. Locating the BOCC within SEL will help assure that collaboration efforts will flourish between F\&O and researchers in EED. This will further provide leadership in electricity infrastructure and building efficiency and will improve the energy efficiency of PNNL's portfolio of facilities.

PNNL researchers are nationally recognized leaders in Electricity Infrastructure and Buildings (EI\&B). The BOCC will be the focal point for creating a Living Laboratory. The BOCC will be the collaboration center for F\&O and counterparts in EI\&B. This collaboration will utilize the PNNL campus as a test bed and proof-of-concept for new technologies. The BOCC test area can be the first step in testing new technologies developed by $\mathrm{R} \& \mathrm{D}$. The BOCC will allow collaboration between R\&D and FMCS specialists. Field testing can be completed by the BOCC staff. The BOCC will also act as the collaboration point between $R \& D$ and facility systems. They will be able to provide required data to $R \& D$ for verification of the new technologies.

An FMCS test lab will be set up in the BOCC and the Power Electronics Lab, in SEL. The FMCS test lab will include multiple manufactures' controller lines, multiple product types (e.g., heating, ventilation, and air conditioning [HVAC], lighting, etc.), and operator work stations that allow programming of each type, meters, etc. The FMCS test lab will provide collaboration space for R\&D and a test bed to provide proof-of-concept for new technologies. This collaboration can lead to expanding R\&D opportunities.

Three areas for immediate collaboration between $F \& O$ and $R \& D$ are smart grid, transactional control, facility re-tuning and audits, DSOM fault detection and automatic diagnostics.

\section{Smart Grid: Transactional Control \& Load Shedding/Demand Response}

PNNL R\&D is a leader in smart grid demonstration that will advance smart grid concepts and bring substantial benefits to the Pacific Northwest and the nation. The BOCC integration into SEL will allow for further demonstration of the smart grid using PNNL facilities. By collaborating with F\&O and R\&D the data, programming and sequence on how to achieve load shedding and Transactive control can be shared. Transactive control is energy, operational, and financial transactions between equipment and the electric power grid using applications, or 'agents' that reside either on the equipment, on local building controllers or in the Cloud. The BOCC will be a demonstration area of these strategies and techniques on facilities at PNNL. It is recommended that load shedding strategies be developed and tested in collaboration with $\mathrm{R} \& \mathrm{D}$. This will provide several benefits to Operations on evaluating peak loads, understanding how to sequence loads to minimize peaks, and learning from R\&D experts. Additionally, R\&D will have a test bed to apply actual strategies on operating facilities to evaluate the impacts on occupants and the maintenance staff and on how to improve the load-shedding strategies. R\&D would also like to collaborate with F\&O to apply VOLTTRON and demonstrate Transactive control. VOLLTRON is a multi-building load curtailment software tool developed by PNNL R\&D staff.

\section{Facility Re-tuning \& Audits}

PNNL R\&D initiated the commercial facility re-tuning project for DOE's Building Technologies Office. The goal of this project is to improve facility operations by transferring the skills to "re-tune" commercial facilities using a series of resources, including training programs and an online interactive 
training curriculum. The re-tuning training is intended to provide building operators, building managers, and energy service providers with the necessary skills to identify no- and low-cost operational problems that plague commercial facilities - and to provide the skills necessary to take corrective action. The retuning training is an online interactive course and can also be taught in a classroom setting. It is recommended that re-tuning training become a requirement for power operators and building engineers to expand their knowledge and give them the skills needed to diagnose, troubleshoot, and solve operational problems. This collaboration in the BOCC can be used to improve the performance of PNNL facilities, increase knowledge of staff, but also to increase the effectiveness of the Building Performance Team by providing access to the FMCS and its data.

\section{DSOM Fault Detection and Diagnostics}

DSOM is a condition-based operations \& maintenance software program designed to provide the facility staff with actions to implement efficient life-cycle asset management. DSOM was developed by researchers at PNNL. The DSOM system is an advanced supervision and diagnostic tool to reduce plant operating and maintenance costs and extend plant life. PNNL uses DSOM in the F\&O group for managing the PNNL campus. The BOCC staff will become responsible for implementing DSOM at PNNL.

The BOCC staff will collaborate with R\&D to develop new dashboards and diagnostic tools. This continued collaboration between groups will provide more opportunities to utilize DSOM at other locations and improve operational effectiveness at PNNL.

One of the major advantages of the DSOM system is its ability to monitor systems instead of just data points. R\&D experts are actively working to develop more fault detection and diagnostics. We expect this to be an expanding collaboration opportunity for the BOCC staff \& EED. In the future, automatic diagnostics will be the core of PNNL's RT-Cx program. It will be important to have in place the appropriate smart sensors to allow for diagnostics to be programmed and built in the future. 


\subsection{Systems}

\subsection{Introduction}

The "SMART ${ }^{3}$ Systems" include the FMCS and DSOM. These systems are at the core of the BOCC and are used to monitor and analyze real-time data to make informed decisions to reduce facility operating costs. The BOCC staff will maintain standardization of FMCS and development of dashboards and tools in DSOM.

\subsection{FMCS Standardization}

The FMCS is one of the core systems for the facilities element. The FMCS system is used to control, monitor, and operate the facilities managed by F\&O. PNNL researchers also use the system to gather experimental data and perform facility analysis research activities. The FMCS Strategy will assure longterm viability of the system to maintain operational control of mission-ready facilities. The FMCS Strategy is the core foundational component to achieve the smartest systems aspect of SMART ${ }^{3}$.

This is accomplished by standardizing graphics (data always in same place), reducing training time when cross-training operators/building engineers with facilities (access is the same in all facilities), and maintaining consistent alarms. The BOCC staff will assist in assuring standards from the FMCS Strategy are implemented in renovation work and new facilities.

\subsection{DSOM Dashboards \& Tools}

DSOM is another core system for SMART ${ }^{3}$ facilities. It is an R\&D-developed software program to be used as a tool for energy management and condition-based operations \& maintenance that is designed to provide the facility staff with actions to implement efficient life-cycle asset management.

The BOCC staff will become responsible for implementation of DSOM at PNNL. This includes maintaining links, alarms, graphics, etc. The BOCC staff will also collaborate with R\&D to develop new dashboards and diagnostic tools. This continued collaboration will provide more opportunities to utilize DSOM at other locations and improve operational effectiveness at PNNL. This will also demonstrate that PNNL is a Living Laboratory.

DSOM is currently integrated into PNNL daily operations and is used to track performance against energy goals. To improve and fully utilize DSOM and to allow for cost-saving opportunities, additional dashboards and diagnostic tools are required. Bringing real-time data to facility occupants will allow them to make informed decisions to reduce energy consumption and also allow them to see how their choices directly affect actual usage. Bringing real-time data to building managers and building engineers will allow for more informed decisions, helping to improve operations and reduce energy usage.

The following four main objectives are outlined to achieve this utilization:

\section{Develop Facility Dashboards (Occupancy interactions with DSOM)}


- Display real-time utility usage against goal

- Highlight sustainable features of each facility

- Highlight occupant energy reduction opportunities

- Provide a temperature map

2. Create Web-based Energy Charts \& Facility Scorecards (building manager and building engineer interactions with DSOM)

- Energy/goal charts: Convert manually created charts into DSOM

- Enhanced Plan of the Day: Create a web-based facility health and status: weather, energy goals, override reports, amount of alarms in past 24 hours, etc.

3. Provide Institutionalize Diagnostics (heat pumps/chillers/boilers/air handler units/terminal units)

4. Develop New Tools (i.e., Outlook scheduling tool, Core Business Hours Verification tool, energy intensity mapping)

One example of a new tool that was conceived by the BOCC staff and then developed by R\&D is the Core Business Hours Verification tool. This tool has been directly instrumental in reducing operational costs. The Core Business Hours Verification tool compares actual run hours against expected run hours and identifies excessive overrun.

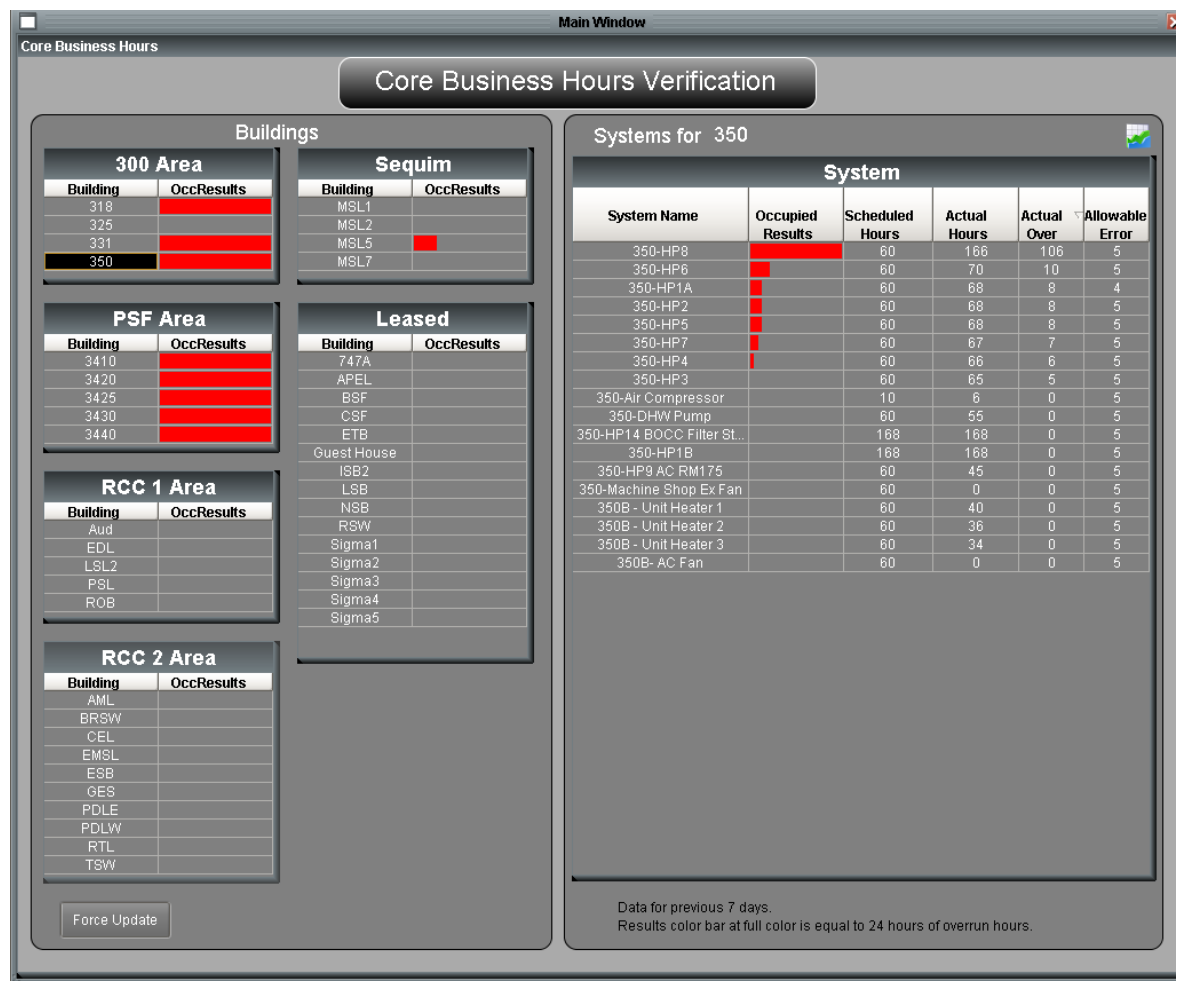

Figure 1. CBHV Tool in DSOM 


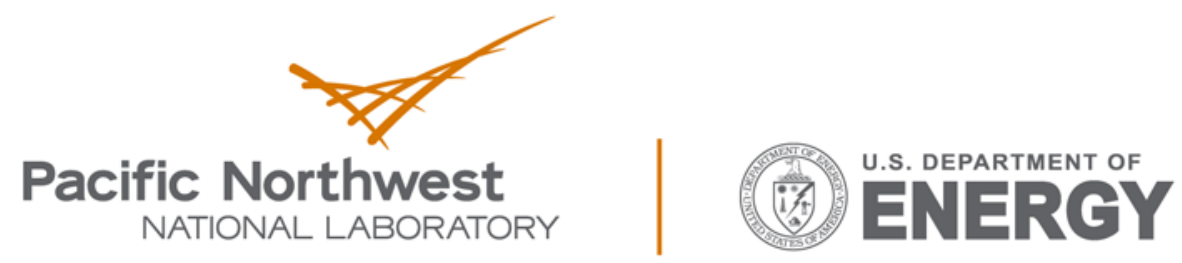

Proudly Operated by Battelle Since 1965

902 Battelle Boulevard

P.O. Box 999

Richland, WA 99352

1-888-375-PNNL (7665)

www.pnnl.gov 